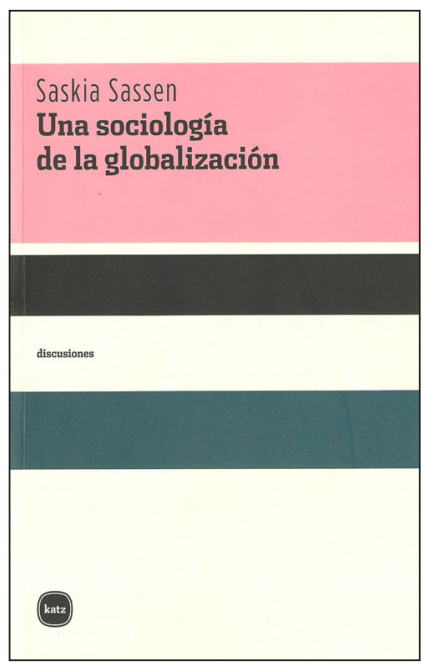

Saskia Sassen

\section{Una sociología de la globalización}

Buenos Aires: Editorial Katz (2007).

\section{Presentación}

El libro que se presenta a continuación parece ser en sí mismo un casual testimonio de su contenido. Su publicación en español prácticamente coincide con su edición en inglés, lo que es posible gracias a las nuevas tecnologías de información y comunicación en un mundo global cada vez más conectado y coordinado. Este simple hecho era impensable hace algunos años, incluso hoy no es tan generalizado, ya que aún persisten barreras técnicas y burocráticas para una completa simultaneidad en los procesos de edición en diferentes idiomas y países.

Precisamente, la tendencia creciente de globalización, coordinación y la superación de antiguas barreras y concepciones históricas, así como las consecuencias sociales, políticas y económicas de estos procesos, son el objetivo central de esta sociología de la globalización.

Saskia Sassen parece sintetizar en este libro una serie de trabajos anteriores sobre diversos temas, como la migración internacional femenina, la proliferación de la red Internet, la consolidación de una nueva geoeconomía global, etc., y lo hace en función de las categorías más clásicas de la sociología; es decir, en función de las estructuras, las instituciones y la acción.

El eje fundamental del argumento y objeto de estudio que propone la autora tiene que ver con la pérdida de centralidad de la categoría Estado-nación para el análisis de la globalización, y junto con ello, con la imbricación de escalas locales y globales a través de procesos de desnacionalización creciente.

El libro se organiza en siete capítulos, donde el primero, denominado "elementos para una sociología de la globalización”, es el más sugerente y novedoso. El resto aparece como una compilación de diferentes ejemplos conocidos o manifestaciones de procesos que tienen que ver con lo descrito conceptualmente en la primera parte, haciendo por momentos reiterativo el argumento.

Así, a partir de las ideas de desnacionalización y de procesos multiescalares, Sassen analiza lo que para ella son los elementos constitutivos iniciales de una sociología de la globalización; 1) la relación del Estado frente a la nueva economía y las redes 
digitales; 2) la recuperación de la importancia del lugar y de las prácticas sociales en la ciudad global; 3) la conformación de los movimientos migratorios internacionales; 4) la formación de nuevas clases globales y la emergencia de actores locales en la política global; y finalmente 5) la consolidación de nuevas formaciones sociales globales.

\section{Tesis centrales de una sociología de la globalización}

El libro comienza señalando la siguiente afirmación: los procesos transnacionales como la globalización politica, económica y cultural enfrentan a las ciencias sociales con desafíos teóricos y metodológicos nuevos. Esto es así ya que lo global trasciende el marco exclusivo del Estado-nación, por lo que compromete directamente algunos de los supuestos clave de las ciencias sociales, a saber: a) la consideración del Estado-nación como contenedor de los procesos sociales y b) la correspondencia implícita entre territorio nacional y lo nacional como característica.

Esta idea es uno de los ejes centrales del texto e implica que lo global también reside en cierta medida en lo nacional. Se parte de la premisa de que si un proceso o entidad se encuentre dentro del territorio de un Estado soberano no significa que sea un proceso o entidad nacional, puede ser también una localización de lo global o bien una entidad nacional que está en proceso de desnacionalización.

Por lo tanto, lo que se intenta designar con el término globalización y que en este libro es sujeto de una sociología tiene que ver, por un lado, con la formación de procesos e instituciones explícitamente globales, pero también con los procesos que no pertenecen necesariamente a la escala global y que sin embargo forman parte de la globalización, inmersos en territorios nacionales y que se conectan a la globalización a través de diferentes redes o entidades transfronterizas. En este sentido, los procesos globales logran desestabilizar las jerarquías centradas en el Estado-nación.

Por ejemplo, los centros financieros de las ciudades globales por un lado y las organizaciones del tipo OMC por el otro son dos formas locales y globales que operan en un nivel multiescalar. "Ninguno de estos ejemplos puede incorporarse fácilmente en las jerarquías anidadas del pasado, según las cuales todo lo que es supranacional queda por encima del Estado y todo lo que es subnacional queda por debajo de él (...) Se trata entonces de un sistema multiescalar que opera a través de todas las escalas y no, como suele afirmarse, de un simple ascenso a través de ellas gracias a los nuevos desarrollos de la comunicación” (pp. 28-29).

El resultado es una reformulación de las escalas en términos de los lugares estratégicos que articulan el nuevo sistema. Así, con el debilitamiento o la desarticulación parcial de lo nacional en tanto unidad espacial, se dan las condiciones necesarias para que asciendan otras escalas y unidades espaciales. Entre ellas, la subnacional: ciudades y regiones, y la supranacional: mercados electrónicos globales.

Aunque todo esto en realidad no altera las fronteras geográficas del territorio nacional, sí cambia el significado de la autoridad exclusiva del Estado sobre dicho territorio (p. 47). Hay 
un cambio de rol del Estado, que por un lado renuncia a formas tradicionales de control y por otro registra nuevas modalidades de participación que ayudan a potenciar la globalización.

A partir de este marco conceptual novedoso, Sassen intenta analizar diferentes procesos característicos de la globalización, enfatizando cómo cada uno de ellos constituye una forma de imbricación local-global en diferentes escalas y cómo cada uno de ellos refleja diferentes niveles de desnacionalización.

\section{El Estado frente a la economía global y las redes digitales}

El análisis académico tradicional sobre la relación entre el Estado y la globalización presenta, en la lectura de Sassen, tres posiciones básicas (p. 61):

- $\quad$ La globalización victimiza al Estado y disminuye su importancia.

- Es poco lo que ha cambiado y en última instancia los estados siguen haciendo lo que siempre han hecho.

- El Estado se adapta e incluso puede verse transformado por la globalización, con lo que asegura su rol en el proceso.

Todas estas posiciones comparten el supuesto de que lo nacional y lo global se excluyen mutuamente. Sin embargo, la inserción de lo global requiere una eliminación sólo parcial de la circunscripción nacional, y por lo tanto, supone la participación del Estado incluso cuando éste renuncie a su papel regulador de la economía. Si bien con el fortalecimiento de los actores económicos, en palabras de Sassen, la autonomía del Estado se ha evaporado (p. 96), éste constituye un espacio estratégico para la globalización, no sólo porque en él se encarna la capacidad de cumplir objetivos específicos gracias a la centralización del poder coercitivo, sino también porque ofrece un dominio donde es posible articular las estrategias de acción colectiva (p. 99). Así, a diferencia de quienes postulan la declinación del Estado, Sassen plantea que algunas de las características de la globalización económica posibilitan una mayor diversidad de formas de participación estatal. Todos estos nuevos procesos se ven intensificados, además, gracias a las nuevas dinámicas que posibilitan las tecnologías de información y comunicación, específicamente la digitalización de la economía.

"En síntesis, el espacio digital privado del mercado global de capitales se intersecta al menos de dos maneras específicas con el ámbito de la autoridad estatal y con el derecho. Por un lado la intersección se da mediante la introducción en las políticas de Estado nacionales, de un nuevo tipo de normas que reflejan la lógica operativa del mercado global de capitales. Por otro lado, una segunda intersección se da mediante la inserción parcial de los mercados financieros digitales en los centros financieros concretos, lo que devuelve al mercado global de capitales, al menos en parte, al ámbito de los gobiernos nacionales." (pp. 122-123). Es decir, lo nacional y lo global están íntimamente imbricados en procesos complejos de articulación en diferentes escalas. 


\section{Ciudades globales: la recuperación del lugar y las prácticas sociales}

En este contexto, la ciudad global ${ }^{1}$ aparece como el lugar de las prácticas de producción de la globalización, lo que es central para comprender las formas de articulación local-global. En palabras de Sassen: "El análisis de la globalización económica centrada en la prácticasrecupera las categorías de lugar y de procesos de trabajo, categorías que suelen soslayarse en los estudios centrados en la hipermovilidad del capital y el poder de las empresas multinacionales" (p. 126). El análisis económico de las ciudades globales recupera la gran variedad de empleos y de culturas de trabajo, tanto de los sectores poderosos como de los desfavorecidos, que forman parte de la economía global, pese a que algunos no son reconocidos como tales. Dicho análisis permite examinar la posibilidad de que existan nuevas formas de desigualdad derivadas de la globalización económica (p. 126). Es decir: "Permite preguntarse si a partir de la década de los ' 80 fenómenos tales como el poder, la movilidad del capital, la desigualdad, el desamparo, la clase profesional, las pandillas o la política adquieren modalidades, aunque sólo sea en algunos de sus componentes, que permitan distinguirlos de modo suficiente de los fenómenos anteriores y, como consecuencia, especificarlos como nuevos, aun cuando en términos generales esto sea difícil de establecer” (p. 127).

Este argumento es fundamental para los estudios urbanos contemporáneos, ya que permite situar a la globalización como fenómeno de base para el desarrollo de diferentes objetos de estudio. En este sentido, Sassen devuelve a la ciudad, en el contexto de globalización, su carácter de prisma para la teoría social; es decir, como un espacio con capacidad de producir conocimiento sobre las principales transformaciones de una época histórica (p. 128).

\section{La conformación de los movimientos migratorios internacionales}

En la globalización, y específicamente en el espacio de la ciudad global, adquiere importancia el estudio de las micro estructuras de lo global, como son los movimientos migratorios internacionales. Ellos son otro ejemplo de articulación en diferentes escalas que superan el contexto del Estado-nación.

La migración internacional, tradicionalmente caracterizada y explicada a partir de los factores de atracción y expulsión, adquiere nuevas dimensiones en el contexto de globalización. Ésta produce un efecto puente que genera nuevos imaginarios y condiciones materiales a partir de los cuales la emigración aparece como una opción cuando antes no lo era. Hoy, el aumento de la exportación organizada de mano de obra tanto legal como ilegal agrega una nueva dinámica a las anteriores, una dinámica de mercado que no se ajusta a lo observado anteriormente y que debe ser objeto de nuevos marcos de observación y análisis de una sociología de la globalización. Las nuevas tendencias de articulación de los movimientos migratorios internacionales con las condiciones fundamentales de la globalización revelan la intersección de sistemas formales y

\footnotetext{
$1 \quad$ Las características de las ciudades globales son ampliamente tratadas en el texto; sin embargo, se dan por entendidas a partir de los trabajos anteriores de la misma autora. Más allá de su descripción detallada, interesa destacar el carácter articulador de la ciudad global, de las múltiples escalas de imbricación entre lo local y lo global, así como de los procesos de desnacionalización.
} 
de prácticas concretas. Es aquí donde algunas de las dinámicas globales y desnacionalizadas adquieren relevancia para entender los flujos migratorios actuales, entendidos como una forma de microestructura de lo global.

\section{Nuevas clases globales y actores locales en la política global}

En este proceso, comienzan a distinguirse formaciones sociales globales reconocibles. Las clases globales emergentes son resultados parciales y específicos que no constituyen necesaria ni intrínsecamente formaciones sociales nuevas, sino que pueden surgir de un reposicionamiento subjetivo y autorreflexivo en un marco transnacional de ciertas condiciones o prácticas sociales ya existentes (p. 215). Es decir, aunque ya existen cobran nueva importancia, nuevas consecuencias, nuevo significado y nueva manifestación política.

Las principales clases globales identificadas por Sassen son:

- Elites transnacionales: una de sus características es su posición intermedia entre lo nacional y lo global. Profesionales de control de lo medios de producción más que propietarios. Clase móvil entre los diferentes puntos cambiantes de la nueva geografía.

- Redes transnacionales de funcionarios públicos: redes muy poderosas de funcionarios públicos a cargo de ciertas tareas fundamentales para el desarrollo de la economía global corporativa. Su trabajo se orienta a un proyecto global. Clase burocrática global.

- Clase global de los desfavorecidos: gozan de escasa movilidad, no pertenecen a una clase transnacional hipermóvil ni a la nueva élite internacional de la sociedad civil.

Estas nuevas clases, pese a que son globales, se encuentran parcialmente insertas en ámbitos nacionales, lo que es importante para captar su articulación con estructuras de clase nacionales e incluso para saber hasta qué punto las desestabilizan. Se podría decir que cada una de ellas transforma lo global en un elemento parcialmente endógeno de ciertos ámbitos nacionales específicos (pp. 230-231).

Además de la conformación de estas nuevas clases globales, la globalización y las TIC han posibilitado el ingreso de una variedad de actores políticos locales en ámbitos internacionales. Estos constituyen los microespacios y los microactores de la sociedad civil global (p. 238). Con ellos, la ciudad aparece como el espacio político central en la globalización, mucho más que la nación, entre otras razones, porque se abre a los actores políticos informales, que se vuelven más fácilmente invisibles en la política nacional tradicional ( $\mathrm{p}$. 246). En este escenario, las TIC se constituyen como la herramienta fundamental de la nueva política, sin embargo, aunque la red sea global, no toda la actividad se da en ese nivel, lo que es una manifestación más del carácter multiescalar de los nuevos procesos (locales) globales. "Una característica importante de la política local multiescalar es que no está confinada a moverse dentro de un conjunto de escalas jerárquicas anidadas, sino que sus actores pueden acceder directamente a otros actores locales semejantes en el mismo país o en el exterior" (p. 257). 
Así, tanto las clases globales como los nuevos actores políticos locales insertos en la globalización constituyen nuevas formas de imbricación local-global y superan la jurisdicción del Estado-nación. Por lo tanto, se constituyen en objeto de estudio específico de una sociología de la globalización.

\section{Nuevas formaciones sociales}

Finalmente, desde una sociología de la globalización, la perspectiva tradicional del Estado-nación lleva a un nacionalismo metodológico que ya no es útil para comprender los fenómenos surgidos en el nuevo contexto. Se hace necesario pasar de la idea de las fronteras nacionales tradicionales, a la concepción de nuevas demarcaciones fronterizas y nuevas formaciones sociales.

El establecimiento de legislaciones globales y de dominios digitales de alcance global supone una multiplicidad de espacios con demarcaciones fronterizas que pueden operar a escala transnacional, supranacional o subnacional, y donde no entran en juego las fronteras nacionales y geográficas tradicionales (p. 268). Por lo tanto, el interlocutor de esta nueva economía ya no es su contexto o entorno inmediato, sino el conjunto de los demás centros comerciales y financieros importantes del mundo, con los que conforma una geografía transfronteriza estratégica (p. 287). Así, se pierde la jerarquía tradicional de escalas y se observa un reposicionamiento en el significado de lo local y lo global cuando ambos elementos se interconectan en red, ya que cada uno de ellos tiende a volverse multiescalar (p. 298).

Estos son los elementos centrales para una sociología de la globalización que pretenda dar cuenta de los procesos en curso, analizando, como antes estructuras, instituciones y acción. Sin embargo, a partir de un nuevo marco conceptual que supera las categorías más anquilosadas de la sociología tradicional.

Felipe Link

\footnotetext{
Sociólogo, Magíster en Investigación Social y Desarrollo. Candidato a Doctor en Arquitectura y Estudios Urbanos, Pontificia Universidad Católica de Chile.

Correspondencia: falink@uc.cl
} 